\title{
The situation room: a step-by-step procedure toward pandemic influenza preparedness
}

\author{
Miguel Angel Castro-Jiménez ${ }^{1,2}$, Lina María Vera-Cala ${ }^{1,3}$, and Gloria Janneth Rey-Benito ${ }^{2}$ \\ ${ }^{1}$ Universidad Industrial de Santander, Bucaramanga, Colombia \\ 2 Instituto Nacional de Salud, Bogotá, Colombia \\ ${ }^{3}$ University of Wisconsin, Madison, USA
}

\begin{abstract}
In the context of public health surveillance, the situation room might be playing an interesting role as a strategy for early alert and follow-up of a specific public health event and its determinants. The implementation and proper functioning of an influenza situation room monitoring seasonal and pandemic influenza or any other public health event could help to mitigate the impact of the next pandemic on public health in any country, regardless of its level of economic development. This paper suggests some basic steps for implementing an influenza situation room as a strategy of prevention of diseases with the potential to cause new or worsening human pandemics.
\end{abstract}

Keywords: Influenza A virus, epidemiology, disease outbreaks, public health practice

J Infect Dev Ctries 2009; 3(9):649-653.

Received July 08, 2009 - Accepted August 28, 2009

Copyright $\odot 2009$ Castro-Jiménez et al. This is an open-access article distributed under the Creative Commons Attribution License, which permits unrestricted use, distribution, and reproduction in any medium, provided the original work is properly cited.

\section{Introduction}

Public health authorities continue to closely monitor the presence of human cases and deaths from respiratory illness linked to two emerging viruses related to a genus of the Orthomyxoviridae family: influenza $\mathrm{A}(\mathrm{H} 5 \mathrm{~N} 1)$ virus causing disease in birds, humans, and other mammals mainly living in Asia and Africa; and the pandemic (H1N1) 2009 virus with human cases and deaths around the world [1]. The design of strategies for public health surveillance is a necessary task to avoid an outbreak or to decrease the complications of an outbreak should one occur. A situation room (SR) to monitor public health events such as acute respiratory illness related to influenza virus infection (SRI) in any country, regardless of that country's level of economic development, might facilitate that task. This paper suggests some basic steps for implementing an SRI as a strategy of prevention of diseases with the potential to cause new human pandemics and their mitigation if the infection has already begun.

\section{What issues should we take into account when we are planning a $S R$ ?}

In this paper, an SR is defined as a central strategy for the early alert and monitoring of epidemic diseases and their determinants that affect, or that it is believed could potentially affect, human health. Upon early detection of the infectious disease, working within the context of an SR could potentially prevent that illness from migrating to a specific area, thereby preventing the disease from occurring in that a specific area and/or minimizing the consequences of the infection. The following recommendations (or steps) might be considered an initial methodological guideline for epidemiologists and other professionals during the implementation phase of an SR. These steps are modeled on the surveillance of the current worldwide public health problem: the outbreaks of swine and avian influenza.

Step 1 - Defining the public health event: the outbreak of swine/avian flu is considered as the health event under surveillance. However, because a seasonal flu can be present at the time of the onset of a pandemic, some of the factors of seasonal flu will also be included here.

Step 2 - Searching the existing (and new) scientific information to establish and monitor the changes and the onset of the disease and its determinants at two different times: to prevent its arrival in the host country of the SR or to minimize 
its impact if the country has already been affected (see below).

Step 3 - Defining what information is required and its periodicity, taking into account those factors investigated in the previous step and at every time when the pandemic phase changes.

Step 4 - Identifying government and private institutions (local, regional, and international) and other sources that can contribute to facilitate getting the information required. In the international setting, it would be essential to have information produced by several sources such as the World Health Organization and its regional offices, the Food and Agriculture Organization of the United Nations, the World Organization for Animal Health, the European Centre for Disease Prevention and Control, Promedmail, the Food and Drug Administration, PubMed, and some international journals.

Step 5 - Defining strategies for capturing information from the different sources: the SRI must have Internet access and a valid Email address, web site, telephone, fax, and other communication strategies. Also, it needs to have a database and corresponding questionnaires specifically designed for capturing essential information.

Step 6 - Maintaining contact with national institutions previously defined, identifying personnel responsible for each institution, and making commitments to share and discuss the information in a timely manner. Also, it should be established how the information will be received from each national or international institution and its periodicity (by fax, Email, telephone, mail, searching in a specific website, or a combination of these).

Step 7 - Defining the mechanism for validating the information: to define what is the most appropriate method (or methods) for ensuring that information is complete and correct and who is going to be responsible for consulting, confirming, or correcting questionable information.

Step 8 - Making an adequate epidemiologic analysis and disclosure of the received information: an epidemiologist working at SRI must have the ability to quickly analyze, interpret and prioritize information, reports, papers and results that come from the several national and international sources. Notifications are made through immediate, daily, weekly, and monthly summaries according to the priority given to the received information. However, in critical times, it is required that this report be updated several times a day.

Step 9 - Establishing what institutions should receive the analyzed information through periodic reports.

Step 10 - Defining the mechanism of feedback from the decision makers toward the professionals working at SRI.

Step 11 - Defining the mechanism of feedback from the SRI toward the national and international institutions which are the sources of information. Once again, the frequency and the content of these reports vary according to the situation.

\section{How can we develop the second step?}

$2 \mathrm{~A}$. Defining the known or suspected risk factors that modify the risk of the presence of the public health event in any country (global information) such as the following:

a. The presence of a new virus against which there is no human immunity, the presence of antigenic shift or both: Influenza A viruses including the recently emerged pandemic (H1N1) 2009 virus of the swine influenza and $\mathrm{H} 5 \mathrm{~N} 1$ avian influenza are the major concerns among public health authorities. Influenza A (H1N1) virus was responsible for the 1918-1919 influenza pandemic known as the Spanish flu [2,3]. In a sample of clinical patients in Iran, the predominant subtype of human influenza virus was $\mathrm{A} / \mathrm{H} 3 \mathrm{~N} 2$, followed by $\mathrm{A} / \mathrm{H} 1 \mathrm{~N} 1$. The authors indicate that, in particular, the phylogenetic analysis on $\mathrm{H} 1$ showed some genetic drifts from vaccine strains [4].

b. The presence of avian or swine influenza disease among birds, pigs, or other mammals with risk of human transmission: Highly pathogenic H5N1 virus was isolated from a farmed goose in China in 1996. Then, in 1997, outbreaks of highly pathogenic H5N1 were reported in poultry at farms and live animal markets in Hong Kong. In that year, also in Hong Kong, the first infection by H5N1 in humans was reported, with 18 cases and six deaths (casefatality ratio: $33.3 \%$ ) (5). In the Americas, the presence of virus with high pathogenicity in poultry 
(H7N3) as well as virus with low pathogenicity (H5N1) were reported [5,6]. The results of two studies showed that domestic cats are at risk of disease or death from $\mathrm{H} 5 \mathrm{~N} 1$ virus; they can be infected by horizontal transmission and other routes of exposure and cause systemic disease $[7,8]$.

c. The development and availability of vaccines and treatments against the virus around the world: during 2007: it was announced that the first vaccine for humans against the $\mathrm{H} 5 \mathrm{~N} 1$ virus had been approved. It was showed that 45 percent of individuals developed antibodies at a necessary level to reduce the risk of getting influenza; the most common adverse effects reported were pain at the injection site, headache, general ill feeling, and muscle pain [9]. Recently, a reported study indicated that an intranasal flu vaccine represents an approach to a cross-protective vaccine against both seasonal as well as possible a pandemic influenza $A$ virus infections [10]. Currently, the Federal Government of the United States and manufacturers have begun the process of developing a vaccine against the novel $\mathrm{H} 1 \mathrm{~N} 1$ flu virus; this viral agent is susceptible to the effect of antiviral drugs such as Oseltamivir and Zanamivir [11].

d. The presence of adverse effects, or resistance, or changes in response to vaccines and other drugs against influenza: The most frequent adverse effects reported in patients using Oseltamivir (Tamiflu) were nausea and vomiting [12]. However, a group of possible additional adverse effects were observed in Japanese children, such as psychiatric alterations characterized by a higher risk of delirium, abnormal behavior, and self-injury; however, these effects have not been observed in some other studies $[13,14]$. Resistance to Oseltamivir has been also observed [15]. These findings should be monitored if these treatments are needed in the present epidemic of swine flu.

e. The evidence of easy transmission from person to person: Two aspects should be considered in this point. First, once there is efficient person-to-person transmission of the disease, interspecies transmission is no longer a threat to human health. Second, efficient person-to-person transmission would increase the attack rate of the infection. In the present pandemic, there is no evidence of transmission from animals to humans; however, person-to-person transmission is evident. Some human cases of swine flu caused by Influenza A (H1N1) had previously been reported in Europe during 2003 and 2008 $[16,17]$; thus it is not surprising that the present epidemic was caused by this specific virus. Nonetheless, it is very important to note that in a relatively short time Influenza A (H1N1) was able to spread rapidly from person to person with a low casefatality ratio when compared with similar epidemics. In the case of $\mathrm{H} 5 \mathrm{~N} 1$ infection, person-to-person transmission is considered plausible because there have been individuals infected with $\mathrm{H} 5 \mathrm{~N} 1$ without history of contact with dead or sick birds [18-20].

f. The migration of the infected or sick birds toward the host country of the SRI: The identification of routes and the monitoring of the migratory birds which come from affected countries and can be carriers of the $\mathrm{H} 5 \mathrm{~N} 1$ or other related virus are essential points for avoiding the emergence of outbreaks in native birds. Several studies have assessed the role of the movement of wild birds in spreading the influenza virus [21-23].

g. The presence of pig or poultry farms in zones crossed by migratory infected birds: The virus survives in a wet environment; thus it is likely that spread of the contagion to other species of birds can occur through the contamination of water at farms located on the routes of migratory birds [24].

2B. Defining the known or suspected risk factors that could increase or decrease the impact of the epidemic in the country (national information):

a. The arrival of people from countries affected by the epidemic in humans or animals who meet epidemiologic criteria for case (or exposed) definition: It is necessary take into account that the country of birth and the country of residence (and the last country which the person visited in the last month) are different concepts, and then the follow-up of the previously visited countries by the travellers using the information contained in their passports would be useful.

b. The stockpile of antiviral drugs to help in the early response to a flu pandemic, the evidence of pharmacologic resistance to these drugs, and the implementation of vaccines against the influenza or avian influenza virus. One study using several 
mathematical models of influenza vaccination policies showed that lower individual doses, conferring less than maximal protection for those vaccinated, might benefit the community in a greater proportion because the coverage will be greater thus decreasing of the infection attack rate [25].

c. The negative effects of efficient transmission from person-to-person on the social situation because of the migration of people inside the country.

d. The prevalence of chronic diseases in the general population which would increase the number and severity of the complications in patients affected with the pandemic influenza [26].

e. The high level of environmental pollution: it is plausible that particulate matter facilitates the transport of the influenza virus or increases the individual susceptibility to any other respiratory diseases or infections which would increase the risk of having a viral respiratory infection. In fact, this association has been recently discussed [27].

f. The legal or illegal traffic of wild birds, poultry, pigs, and other potentially sick animals among regions from the same country.

g. The availability of adequate numbers of hospital beds, health professionals, epidemiologists, ambulances, and other resources needed for giving adequate medical care to sick, dead, and relatives.

h. The impact of the public health event (morbidity, mortality, absenteeism) on the general population and its impact (morbidity, mortality, absenteeism) on health services and transportation staffs.

\section{Conclusion}

These basic steps can be adapted to any public health event. A method of public health surveillance such as a situation room can be an effective strategy to prevent the arrival of a pandemic or mitigate its consequences in any country if the situation room is adequately tailored to the needs and specific characteristics of that country. The current availability of electronic sources of data and maps has increased the opportunity for having real-time data; however, a part of the tasks of the situation room staff is to ensure the accuracy and the completeness of that information.

\section{References}

1. World Health Organization (WHO) (2009) Influenza A (H1N1): WHO announces pandemic alert phase 6, of moderate severity.. $\quad$ Available from: http://www.euro.who.int/mediacentre/PR/2009/20090611_1.

2. Belshe RB (2005) The Origins of Pandemic InfluenzaLessons from the 1918 Virus. N Engl J Med 353: 2205-2211.

3. Trifonov V, Khiabanian H, Greenbaum B, Rabadan R (2009) The origin of the recent swine influenza $\mathrm{A}(\mathrm{H} 1 \mathrm{~N} 1)$ virus infecting humans. Euro Surveill 14: pii=19193. Available online:

http://www.eurosurveillance.org/ViewArticle.aspx?ArticleId $=19193$.

4. Soltania Z, Hosseinib M, Shahidia M, Hedayatic M, Kheiria MT (2009) ;Molecular Analysis of Human Influenza Virus in Tehran, Iran. Intervirology 52: 63-67.

5. World Heath Organization. H5N1 avian influenza: Timeline of major events. 2009 Mar 23 [cited: 2009 May 13] Available from

http://www.who.int/csr/disease/avian_influenza/Timeline_09 _03_23.pdf.

6. Hirst M, Astell CR, Griffith M, Coughlin SH, Moksa M, Zeng T, et al. (2004) Novel avian influenza H7N3 strain outbreak, British Columbia. Emerg Infect Dis 10: 2192-2195.

7. Kuiken T, Rimmelzwaan G, van Riel D, van Amerongen G, Baars M, Fouchier R, et al. (2004) Avian H5N1 influenza in cats. Science 2004; 306: 241. Sep 2 [cited: 2009 May 2] Available from http://www.sciencemag.org/cgi/content/abstract/306/5694/24 1 .

8. Rimmelzwaan GF, van Riel D, Baars M, Bestebroer TM, van Amerongen G, Fouchier RA, et al. (2006) Influenza A virus (H5N1) infection in cats causes systemic disease with potential novel routes of virus spread within and between hosts. Am J Pathol 168(1):176-83.

9. U.S. Food and Drug Administration. FDA Approves First U.S. Vaccine for Humans Against the Avian Influenza Virus H5N1. 2007 Apr 19. [cited: 2009 May 5] Available from http://www.fda.gov/bbs/topics/NEWS/2007/NEW01611.htm.

10. Alsharifi M, Furuya Y, Bowden TR, Lobigs M, Koskinen A, Regner M, et al. (2009) Intranasal flu vaccine protective against seasonal and H5N1 avian influenza infections. PLoS ONE 4:e5336.

11. Centers for Disease Control and Prevention. H1N1 Flu Daily Update. (2009) May 5 [cited: 2009 May 13] Available from: http://www.cdc.gov/h1n1flu/updates/050509.htm.

12. Jefferson T, Demicheli V, Rivetti D, Jones M, Di Pietrantonj C, Rivetti A (2006) Antivirals for influenza in healthy adults: systematic review. Lancet 367: 303-13.

13. Toovey S, Rayner C, Prinssen E et al. (2008) Assessment of neuropsychiatric adverse events in influenza patients treated with oseltamivir: a comprehensive review. Drug Saf 31: 1097-114. 
14. Smith JR, Sacks S (2009) Incidence of neuropsychiatric adverse events in influenza patients treated with oseltamivir or no antiviral treatment. Int J Clin Practice 63: 596-605.

15. Dharan NJ, Gubareva LV, Meyer JJ, Okomo-Adhiambo M, McClinton RC, Marshall SA, et al. (2009) Infections with oseltamivir-resistant influenza $\mathrm{A}(\mathrm{H} 1 \mathrm{~N} 1)$ virus in the United States. JAMA 301: 1034-1041.

16. Adiego Sancho B, Omenaca Teres M, Martinez Cuenca S, Rodrigo Val P, Sanchez Villanueva P, Casas I, et al. (2009) Human case of swine influenza A (H1N1), Aragon, Spain, November 2008. Euro Surveill 14: 19120. [cited: 2009 May 5]. Available from: http://www.eurosurveillance.org/ViewArticle.aspx?ArticleId $=19120$

17. Gregory V, Bennett M, Thomas Y, Kaiser L, Wunderli W, Matter H, et al. (2003) Human infection by a swine influenza A (H1N1) virus in Switzerland. Arch Virol 148: 793-802.

18. Kandun N, Wibisono H, Sedyaningsih ER, Hadisoedarsuno W, Purba W, Santuso H, et al. (2006 ) Three Indonesian Clusters of H5N1 Virus Infection in 2005. N Engl J Med 355: 2186-2194.

19. Ungchusak K, Auewarakul P, Dowell SF, Kitphati R, Auwanit W, Puthavathana P, et al. (2005) Probable Person to Person Transmission of Avian Influenza A (H5N1). N Engl J Med 352: 333-340.

20. Yang Y, Halloran ME. Sugimoto JD, Longini IM (2007) Detecting Human-to-Human Transmission of Avian Influenza A (H5N1). Emerg Infect Dis 13: 1348-1353.

21. Feare CJ (2007) The role of Wild Birds in the Spread of HPAI H5N1. Avian Dis 51(1 Suppl): 440-447.
22. Lei F, Tang S, Zhao D, Zhang X, Kou Z (2007) Characterization of H5N1 Influenza Viruses Isolated from Migratory Birds in Qinghai Province of China in 2006. Avian Diseases 51(2): 568-572.

23. Weber TP, Stilianakis NI. Ecologic Immunology of Avian Influenza (H5N1) in Migratory Birds (2007) Emerg Infect Dis. 13(8): 1139-1143.

24. Cox NJ, Subbarao K (2000) Global Epidemiology of Influenza: Past and Present. Annu Rev Med 51: 407 - 421.

25. Riley S, Wu JT, Leung GM (2007) Optimizing the Dose of Pre-Pandemic Influenza Vaccines to Reduce the Infection Attack Rate. PLoS Medicine 4: 1032-1040.

26. Ramaswamy M, Groskreutz DJ, Look DC (2009) Recognizing the importance of respiratory syncytial virus in chronic obstructive pulmonary disease. COPD 6: 64-75.

27. Wong CM, Yang L, Thach TQ, Chau PY, Chan KP, Thomas GN, et al. Modification by influenza on health effects of air pollution in Hong Kong (2009) Environ Health Perspect 117: 248-53.

\section{Corresponding Author}

Miguel Ángel Castro-Jiménez

Universidad Industrial de Santander, Facultad de Salud

Centro de Investigaciones Epidemiológicas

Carrera 32 No. 29-31 (Piso 3), Bucaramanga, Colombia

Telefax: 5776345781

Email: mcastro2505@yahoo.es

Conflict of Interest: No conflict of interest is declared 